\title{
ÁLVARO CUNQUEIRO NA HISTORIA DO TEATRO GALEGO
}

Laura Tato Fontaíña

Universidade da Coruña

doi:10.17075/mucnoc.2014.036 

Forcadela, M. / T. López / D. Vilavedra (coords.) (2014): Mil e un cunqueiros. Novas olladas para un centenario, Santiago de Compostela, Consello da Cultura Galega. doi:10.17075/mucnoc.2014. pp. 725-736

Desde a perspectiva da historia do teatro, Álvaro Cunqueiro (1911-1981) forma parte do Grupo de Enlace (Tato Fontaína 2000: 455), que está constituído por a unha serie de autores que actuaron de elo entre o que intentara ser a dramaturxia de preguerra e as novas promocións do teatro independente e que, en moitas ocasións, serviron de modelo para as seguintes xeracións. A súa extraordinaria orixinalidade maniféstase na produción dramática do mesmo xeito que na obra narrativa. Como dramaturgo, Cunqueiro iniciara a súa andaina antes do 36, durante a República, e aínda que maior parte das pezas escritas neses anos están perdidas, sabemos da súa existencia pola resposta que o propio autor preparou para unha enquisa que Xosé Filgueira Valverde (1991) elaborou para o Seminario de Estudos Galegos. Nela, Cunqueiro informaba, con data do 7 de marzo de 1936, que contaba no seu haber con dúas obras dramáticas inéditas: Lume nas cerdeiras. Ópera ao xeito das romeirías, e mais Rua 26. Farsa. O subtítulo da primeira inclínanos a pensar que respondería a aquelas propostas de Antón Vilar Ponte coas que o ilustre polígrafo pretendía que se creasen libretos inspirados en lendas e tradicións populares para a renovar os coros populares. Da segunda, publicouse o «Diálogo limiar» na revista Yunque, en 1932. Tamén coñecemos desta mesma época o «Prólogo» dunha terceira obra, Xan, o bo conspirador, datado en 1933 e publicado pola revista Grial en 1978. Esta última non fora incluída polo autor na resposta ao cuestionario de Filgueira Valverde.

Os dous fragmentos conservados de Rua 26 (Diálogo limiar) e mais de Xan, $o$ bo conspirador presentan unhas propostas dramáticas absolutamente novas no panorama teatral dos anos trinta pola súa modernidade e singularidade. As coincidencias que hai entre estas dúas obras de preguerra foron sinaladas xa por Teresa López:

Ambas as pezas comparten a aparente simplicidade e a abstracción como características da sua proposta escénica. Alén diso, mesmo nunha leitura superficial, é fácil reparar na existéncia de paralelismos entre elas. Citemos como exemplo a construción dual dos personaxes (o home con cravata / o home sen cravata en Xan; o home branco / o home negro en Rua), a fiestra como elemento configurador do espazo escénico, o obxecto- 
talismán desvinculado da sua finalidade que pode aparecer en escena (o anteollo en Rua) ou formar parte dunha historia narrada por un personaxe (o quebranoces en Xan), o discurso das personaxes como veículo para a introdución de fabulacións que funcionan a modo de parábolas — nun procedimento en todo semellante ao utilizado nas obras narrativas_-, a parente insisténcia en precisar a idade que se presenta inútil ben pola sua permanéncia acronolóxica (a muller en Rua), ben pola imposibilidade de fixá-la con exactitude (a nena da fiestra en Xan), a reflexión metaliterária, en Rua virada cara á reivindicación da imaxinación como motor da criación, en Xan centrada na construción dramática, na incorporación de elementos metateatrais e na preocupación pola adecuación na nomenclatura de categorias ficcionais (o conto / o sucedido). Algúns destes trazos serán familiares ao leitor asíduo de Álvaro Cunqueiro, mesmo ao da sua poesia (López 1995: 15).

A primeira peza dramática de Álvaro Cunqueiro escrita despois de 1936 apareceu incluída na novela Crónicas do Sochantre, publicada en 1956, e leva como título Función de Romeo e Xulieta, famosos namorados. Trátase do breve texto da representación que o macabro grupo do Sochantre realiza en Comfront, onde foron confundidos cunha compañía de cómicos. A versión de Cunqueiro ten pouca relación coa traxedia de Shakespeare. A cidade de Verona acaba de ser liberada do asedio suízo e espera ansiosa a axuda necesaria para remediar a escaseza de alimentos, mais o correo o que trae é unha mensaxe para dona Xulieta. En plena lectura da preciosa carta de amor, comeza a anoitecer e os actores recuperan a súa forma de esqueletos; o público foxe arrepiado e fica en escena unha nena esfarrapada que chora porque "non había Romeo, nin memoria, nin lirios». A recreación persoalísima deste tema de Shakespeare tivo a súa continuación con O incerto señor don Hamlet, príncipe de Dinamarca, que saíu do prelo en 1958.

O proceso de xestación e escrita foi lento e prolongado, pois, en 1955, Cunqueiro comunicaba xa a Francisco Fernández del Riego que pensaba escribir unha obra teatral sobre o tema: «Tan axiña o remate, poreime a un tomo de teatro galego: Un Hamlet, que xa teño matinado, e dúas pezas máis, unha romántica, outra do noso tempo" (Cunqueiro 2003: 96). Tamén comentou o asunto nun artigo publicado o ano seguinte en La Voz de Galicia, aínda que cun final diferente ao que escribiu despois: 
Todos estos días estuve meditando las hamletianas dudas y los inciertos temores, porque me ha venido la ventolera de escribir una pieza teatral cuyo tema sea la muerte de Hamlet. Llegan a Elsinor los cómicos — los de la comedia del arte italiana: Pantalón, Escaramuza, Arlequín, Colombina...- - y Hamlet escribe para ellos una fábula. La están leyendo Hamlet y los cómicos, pero el usurpador y la reina, que asisten escondidos al ensayo, intervienen para exculparse, y los cómicos, errando el luego, hacen que Hamlet y su madre mueran envenenados. El usurpador queda solo (Rivera 2001: 116).

Ademais de brillar con luz propia dentro do panorama teatral, o Don Hamlet abriría as portas á posibilidade de que o teatro galego volvese aos escenarios, pois o autor conseguiu, despois de superar moitas pexas, que se estrease na Coruña en 1959. O poeta Antón Avilés de Taramancos, que colaborara na montaxe como axudante de dirección, deixou unha crónica das peripecias que tiveran que superar para poder estreala. Contaba Avilés que a prohibición do censor local, Serrano Castilla, só puido ser superada pedindo axuda a Manuel Fraga, Secretario de Arias Salgado, Ministro de Información e Turismo:

Naquel tempo, ademais de ser o galego unha lingua represa, tempo no que ao cú se lle chamaba pómpis e os eufemismos campeaban coa validez das palabras lexítimas, a obra de Cunqueiro, tan directa na sua linguaxe tiña que espertar non somente a carraxe da censura polo idioma en sí, senón o furor de Serrano Castilla (censor de turno e do fielato da cultura) quen dixo cando lle presentamos o libro: "Voy a llevar a Don Hamlet al paredón". [...]

Daquela era Secretario ou Subsecretario do Ministerio de Información e Turismo baixo orde de Arias Salgado, Manolo Fraga Iribarne. Non sei se foi Antonio Molina, chanceler do consulado de Uruguai, que se lle ocorreu dicerlle a Cunqueiro que aí era onde tiña que insistir xa que eran antigos cońecidos ou amigos. O telefonazo a Madrid dou un resultado imediato. Ao día seguinte veu Serrano Castilla á tertúlia do Café Galícia cun escrito autorizando a representación da obra. Fixo un panexírico de Cunqueiro como escritor e gabou o traballo que vínamos a facer a prol da cultura e da doutrina do Glorioso Movimento Nacional. Serviamos de exemplo para as novas xeracións.

A estrea do Incerto Señor Don Hamlet, Príncipe de Dinamarca, levou-se a cabo no Teatro Colón da Coruña, tal como tiñamos proxectado, nos días primeiros de Xuño de 1959 (Avilés de Taramancos 1991: 86-88). 
Porén, da correspondencia de Cunqueiro o que se deduce non é exactamente isto, senón que tanto o autor como o Grupo de Teatro de Cámara da ACI, dirixido por Antonio Naveyra Goday, contaban con poder estreala en Santiago de Compostela, o 25 de xullo, día do Apóstolo (Rivera 2001: 157) e que os responsables da delegación de Información e Turismo da Coruña pediran autorización a Madrid (Rivera 2001: 155). A prohibición da estrea, e do libro, tivo unha enorme repercusión fóra do ámbito galego e foi comentada por Radio Espańa Independente, «a mítica Pirenaica» (Cabana 2007: 33) e por Luís Seoane na Arxentina (Braxe e Seoane 1996: 90-93). Tampouco se chegou a representar nin en Santiago de Compostela nin en Vigo, de forma que as únicas cidades en que puido verse o Don Hamlet de Cunqueiro foron A Coruña e Lugo. Da representación nesta última vila deu cumprida conta Dario Xoán Cabana (2007) e, de feito, sería nesta mesma cidade onde se convocaría o primeiro certame de teatro da ditadura, o Certame do Miño, en 1960.

Tanto se Serrano Castilla foi o único responsable da censura da obra como se non o foi, a estrea do Don Hamlet marcou un fito na historia do teatro galego e, segundo conta Avilés de Taramancos, tamén foi a primeira manifestación pública e conxunta dos galeguistas de posguerra:

Toda a Galícia viva estivo presente naquel día. De Vigo viñeran Paz Andrade, Fernández del Riego, Isla Couto, os Álvarez Blázquez, Celso Emilio... De Compostela, García Sabell, Manuel Beiras e os seus fillos, Ramón Pińeiro, Sixto Seco... De Lugo, Manuel María, Novoneyra... De Ferrol, Carballo Calero e Tomás Barros. O que era a galeguidade, que moita se perdeu. Ao final, despois de baixar o pano e de aplaudir a Álvaro Cunqueiro e Antonio Naveira nun abrazo total, erguemo-nos todos e cantamos por primeira vez en público despois de moitos anos o Hino Galego con ar de marcha triunfal (Avilés de Taramancos 1991: 88).

A pesar do éxito e da aclamación pública, parece que non todos os amigos gustaron da obra e que, aínda que non o declarasen en público, si que o fixeron en privado; entre estes figuraban algúns dos máis significados galeguistas da altura, como Ramón Piñeiro (Cabana 2001: 31) e Ánxel Fole (Cunqueiro 2003: 147).

A estrea de Don Hamlet serviu para resucitar vellas polémicas que quedaran superadas había moitos anos, na época do Seminario de Estudos Galegos. Os argumentos que se utilizaron para atacar a Cunqueiro poden dar idea do retroceso 
que sufrira a sociedade galega con respecto da súa propia autoestima: por unha banda, o tema foi acusado de ser "pouco galego» e, pola outra, os eruditos alporizábanse perante a ousadía de verter a Shakespeare ao galego. De todos os xeitos, o que máis ofendeu ao dramaturgo foi a miopía espiritual e intelectual daqueles que cualificaron o Don Hamlet de parodia do Hamlet de Shakespeare. Non lle faltaba razón a Cunqueiro, pois adiantándose ás máis actuais interpretacións do mito, creara un Hamlet-Orestes-Edipo que enchía parte dos misterios da personaxe dramática máis estudada na historia da literatura universal. A partir da mitoloxía escandinava e actuando por redución sobre a traxedia de Shakespeare, Cunqueiro escribira unha das obras máis orixinais do teatro galego.

A orixinalidade do Don Hamlet radicaba en dous achados fundamentais, un de dimensión ideolóxica: a verdadeira paternidade de Halmar; e outra de dimensión estética: o tratamento formal do texto. Volvendo ás fontes primixenias do mito Hamlet, ás Gesta Danorum, de Saxo Grammaticus, Cunqueiro recuperaba o primitivo costume das raínas dinamarquesas de poderen casar cos seus propios fillos, para cerrar un círculo que ía transformar o mártir creado por Shakespeare nun heroe de traxedia grega. Mais a historia de Hamlet era cońecida por todos, de aí que, como indicou Ricardo Carballo Calero (1981), sexa toda ela un desenlace. Seguindo a liña da súa narrativa, Cunqueiro presentaba a peza como o cumprimento do derradeiro desexo do Hamlet shakesperiano: un dos alabardeiros de Fortimbras, un dos que axudou a transportar o cadáver de Hamlet, descubría en escena a verdade das dúbidas do príncipe de Dinamarca.

Dado que traballaba cunha materia literaria moi cońecida, o dramaturgo actuou por redución de personaxes e da acción, ao tempo que transformaba aos primeiros en ideas, en arquetipos do que representan; o espectador/lector non pode esquecer nunca que está perante unha creación artística, que asiste a unha representación dramática, e así llelo lembran continuamente os propios personaxes. Mesmo o recurso do teatro dentro do teatro, utilizado por Shakespeare, alcanza en Cunqueiro unha nova dimensión, e non unicamente porque a peza que representan os comediantes do Don Hamlet sexa unha creación propia, fronte á que interpretaban os de Hamlet que era unha das obras do seu repertorio, senón porque no dramaturgo galego a función dos cómicos actúa dentro do desenvolvemento da acción como un verdadeiro psicodrama, e así, Halmar interrompe a 
Escaramuza, actor que interpreta o seu papel, para corrixir o texto. A dimensión metateatral de toda a obra foi explicada por Luísa Villalta coas seguintes palabras:

O proceso de Hamlet é unha anagnórise con respeito a si mesmo, que se leva a cabo a través do próprio teatro entendido artaudianamente como unha "curación cruel". O contexto, xa meta-teatral desde o comezo, viu-se invadido polo segundo nível teatral, a pantomima, onde a personaxe levou a cabo unha meta-anagnórise, é dicer, unha solución para a ecuación da que ela mesma é a incógnita (Villalta 1992: 75).

Por último, queremos salientar o acerto de Cunqueiro na utilización do coro como elemento encargado de explicar a simboloxía da obra e de interpretar a conciencia colectiva que condena o parricidio e o incesto, ao tempo que insufla na obra ese ton arcaizante tan característico da súa produción literaria.

Na peza seguinte, A noite vai coma un rio, publicada en 1965, Cunqueiro abandonaba os mitos para realizar unha pequena obra mestra onde predomina o elemento lírico. Dividida nun prólogo, dúas xornadas e mais un epílogo, mantén a unidade por mor de dona Inés e da súa Ama Modesta, por cuxa morada, a Torre, van pasando os fuxitivos dunha guerra. Estes personaxes secundarios (El Rei, o Músico, O Capitán...) alimentan uns instantes o soño de dona Inés, para provocaren, de inmediato, a súa decepción. Atemporal e lírica, dona Inés fica condenada á soidade e a unha constante arela amorosa, porque non ama o Home senón o Amor, e máis en concreto os acenos e palabras de amor consagrados pola tradición literaria occidental na lírica amorosa. Nun breve texto de presentación escrito para o folleto da representación realizada polo Centro Dramático Galego, en 1986, Manuel Lourenzo reproducía unhas palabras do propio Cunqueiro sobre esta peza:

A noite vai coma un río. Tamén nesta ocasión a obra é o propio título, como o incerto señor é Don Hamlet e Merlín se fai Merlín pola familia... Unha estrela engalana o horizonte de Cunqueiro, alquimista de rutas que só por fora da história poden sere vixiadas: Elsinor, Bretaña, Ítaca, Valverde... Existiron e existen os países; deles, alguns son paso: a Miranda de Merlín, o Valverde de dona Inés; quer dicer, son lugares de encontro, escenários para a maravillosa confluéncia de matices que no soño son posíbeis; visitas extemporáneas, amantes imaxinados, aventuras e xestos que son e que non son, aparéncia xeográfica dunha verdade oculta que é verdade por si mesma; obra de poeta, en fin... Quen rebusque na noite profunda simboloxía perderá-se sen remédio; quen se perda na noite, a tua, a de 
dona Inés, atopará, talvez, Valverde; será como aqueles mozos do Grial, que finalmente só encontraron o camińo... A noite vai coma un río... pode ser outra cousa que convite a mergullar? Pode ser outra cousa — pergunto-me- o teatro? «Ese ser tan fráxil que se chama Inés — escrebia-me un dia Cunqueiro- quer sair da soidade, quizaves polo único camiño posíbel. Ela dá o corpo non polo goce carnal, senón por unha fartura de soños compartidos. E dia tras dia fica soa, ollando para os camiños que van e veñen, escoitando o vento que pasa, seguindo coa mirada húmida as carreirińas das estrelas. E alimentando-se de si mesma, no grande deserto humano, que non ten máis oasis que os seus sońos...». No grande deserto humano. Nesa dura, interminábel xeografía (Lourenzo 1986: 7).

$\mathrm{O}$ carácter lírico d'A noite vai coma un río, o seu afastamento da realidade social da súa época e, sobre todo, o feito de que Cunqueiro non utilizase ningunha das técnicas dramáticas que se consideraban de vangarda nos anos setenta provocou que no momento da súa estrea, no ano 1973, houbese ardentes polémicas sobre ela e o autor fose acusado de frívolo e irresponsábel, pois evitara reflectir a realidade social que o rodeaba. $\mathrm{O}$ mellor testemuño sobre o rexeitamento que provocou esta extraordinaria peza nun sector do teatro galego e, ao tempo, do desnortado que andaba ese mesmo sector deixouno escrito Xulio Lago, anos máis tarde, cando el propio dirixiu a súa reposición polo Centro Dramático Galego:

No ano 72 ou 73 asistín en Vigo a unha presentación de $A$ noite vai coma un río, no Auditorio da Caixa de Aforros. Ao día seguinte, atopeime có autor, quen, sabedor da mińa inquedanza teatral, pedíume opinión sobre a súa peza. Non recordo as palabras, mais sí o sentir que lle transmitin: non me gostaba en absoluto. Non pasaba nada. Era discursiva, plana. Era "literatura", moi boa literatura, mais non "teatro». Daquela, e non fai tanto, presumía eu de estar na vangarda nesto do teatro. Pasou o tempo. Intento estar na vangarda. Vou dirixir, cheo de ilusión e de medo, A noite vai coma un río. Tamén cheo de ambición, porque é o máis fermoso e cobizoso texto teatral escrito en galego (Lago 1986: 8).

Publicou tamén Cunqueiro fragmentos de dúas obras inacabadas. En 1961, como apéndice á novela Si o vello Sinbad volvese ás illas, viron a luz dúas escenas da peza de teatro chinés $A$ dama que engañada por un demo elegante quixo mercarlle ao vento a perdiz que falaba, ou A verdadeira historia dun mandarin que por non gastar quedou cornudo. De Palabras de vispera, publicaba en 1974 os dous cadros que cońecemos, nos que asistimos ao confronto que consigo mesmo reali- 
za Afonso vi na véspera da Xura de Santa Gadea, coas sombras de Caín e o incesto a pairaren sobre o futuro Emperador. Por último, en 1980, realizou unha poética versión d'A sentencia dourada, de Lord Dunsany, en que cambiaba o final da peza.

Malia as polémicas que xeraron as súas obras, é indiscutible que Álvaro Cunqueiro é un dos clásicos do teatro galego. Para Cesar Morán, un dos seus grandes méritos foi a súa capacidade para romper coa tradición anterior e a temática autóctona:

A partir de Cunqueiro o estrado galego é un espazo idóneo para nel se ubicaren e se expresaren os elementos universais da traxectoria mítica, cunha feizón orixinal onde as houber e cunha actitude directa canto á presentación ante público lector e espectadores potenciais, de xeito que, unha vez erguido o pano, os personaxes expońen no escenario a súa entraña sen pediren licenza por se deslindaren da canle tradicional (Morán 2011:4). Esa ruptura de Álvaro Cunqueiro coa tradición dramática, galega e non galega, vén dada polo seu rexeitamento aos modelos clásicos e porque ofrece solucións autenticamente actuais. Para Afonso Becerra, o seu vangardismo está integrado no surrealismo e chama a atención sobre a modernidade das súas dramaturxias:

Cunqueiro preséntanos unhas dramaturxias nas que a palabra para dicir das réplicas se integra cunha linguaxe a base de xestos, mímica, luces, sons, obxectos e distribucións espaciais, anotadas na partitura dramatúrxica co mesmo rango de importancia que a linguaxe falada. E isto faino case ao mesmo tempo que Antonin Artaud (1896-1948), surrealista expulsado do grupo surrealista, formulara a teoría revolucionaria do Teatro e o seu dobre (1938), na que rexeita o teatro ao servizo da palabra e preconiza a utilización dunha linguaxe autónoma, nacida sobre a realidade do espazo escénico. Nas primeiras pezas do de Mondoñedo, que son alfaias da dramaturxia surrealista universal, achamos as claves de toda a súa obra (pos)dramática, que é moito máis que literatura: é teatro (Becerra 2011: 16).

Por último, queremos salientar que Álvaro Cunqueiro conforma, con Alfonso R. Castelao e Ramón Otero Pedrayo, a triloxía de dramaturgos clásicos que foron referencia indispensable na refundación do teatro galego (Biscaínho 2007) levada a cabo polos dramaturgos do Grupo Abrente na década dos anos setenta. 


\section{REFERENCIAS BIBLIOGRÁFICAS}

Avilés De Taramancos, A.: «Don Hamlet no paredón», Obra viva, Santiago de Compostela, Editorial Laiovento,1992, pp. 86-88.

Becerra de Becerreá, A.: «Rúa do pracer. Pensamento limiar. O doce aroma das mazás na dramaturxia surrealista de Cunqueiro", Casahamlet. Revista de Teatro, 13, 2011, pp. 13-17.

Biscaínho Fernandes, C. C.: A Escola Dramática Galega na configuración do sistema teatral, Santiago de Compostela, Laiovento, 2007.

Braxe, L. e Seoane, X.: Luis Seoane e o Teatro, Sada (A Coruña), Ediciós do Castro, 1996.

Cabana, D. X.: Cunqueiro e Don Hamlet en Lugo, Lugo, Concello de Lugo, 2007.

Carballo Calero, R.: "O incerto señor Don Hamlet, príncipe de Dinamarca», Grial, 72, 1981, pp. 263265.

Cunqueiro, Á.: Cartas ao meu amigo. Epistolario mindoniense a Francisco Fernández del Riego, Vigo, Galaxia, 2003.

Filgueira Valverde, X.: «Presentación», en Autopoética e Poesías. Autógrafos e Inéditos de Álvaro Cunqueiro, Santiago de Compostela, Consello da Cultura Galega, 1991.

Lago, X.: «Palabras para $A$ Noite vai como un Río», en Á. Cunqueiro, A noite vai como un río, de Álvaro Cunqueiro, Santiago de Compostela, Centro Dramático Galego, Xunta de Galicia, 1986, p. 8.

López, T.: «Introdución», en Á. Cunqueiro, Rúa 26. Diálogo limiar, Santiago de Compostela, Editorial Laiovento, 1995.

Lourenzo, M.: "A noite vai como un río», en Á. Cunqueiro, A noite vai como un río, de Álvaro Cunqueiro, Santiago de Compostela, Centro Dramático Galego, Xunta de Galicia, 1986, p. 7.

Morán Fraga, C.: «Un ollar descontinuo ao teatro de Cunqueiro», Casahamlet. Revista de Teatro, 13, 2011, pp. 4-12.

Rivera Pedredo, D.: Álvaro Cunqueiro. 100 artigos, A Coruña, A Voz de Galicia, 2001.

Tato Fontaíña, L.: "O teatro desde 1936», en A. Tarrío Varela (coord.), Galicia Literatura XXXIII. A literatura desde 1936 ata hoxe: poesía e teatro, A Coruña, Hércules de Ediciones, 2000, pp. 442-527.

VIllalta, L.: O Don Hamlet de Cunqueiro: unha ecuación teatral, Santiago de Compostela, Editorial Laiovento, 1992. 
